\title{
REVISITANDO 0 PRIMEIRO MODELO FREUDIANO DO TRAUMA: SUA COMPOSIÇÃO, CRISE E HORIZONTE DE PERSISTÊNCIA NA TEORIA PSICANALİTICA
}

Antônio Luiz Pereira de Castilho

Antônio Luiz Pereira
de Castilho
Mestre em
psicologia pela
UFMG, na área
de Estudos
Psicanalíticos.
Especialista em
Teoria Psicanalítica
pela UFMG.

Antônio Luiz Pereira

de Castilho

Mestre em

pela

de Estudos

Psicanalíticos.

pela UFMG

\begin{abstract}
RESUMO: Revisita-se a construção do primeiro modelo freudiano do trauma, o eixo da chamada teoria da sedução (1896). Seus componentes e dinâmica são examinados e discutidos. O paradoxo presente na mencionada teoria é registrado, bem como a reformulação por parte de Freud do fundamento de sua doutrina através da postulação da pulsão e da sexualidade infantil. Por fim, ao lado da engenhosa e singular maneira pela qual aquele modelo do trauma articula seus elementos, um horizonte de persistência daquela abordagem é ainda afirmado na esfera da teoria da sedução generalizada.
\end{abstract}

Palavras-chave: Trauma, teoria da sedução, pulsão, sexualidade infantil, teoria da sedução generalizada.

ABSTRACT: Revisiting the first Freudian model of trauma: its composition, crisis and horizon of persistence in the psychoanalytical theory. The author revisits the building of the first Freudian model of trauma, the axis of the so-called theory of seduction (1896). Its components and dynamics are examined and discussed. The paradox inside the mentioned theory is registered, and also Freud's reformulation of the basis of his doctrine by the postulation of drive and infantile sexuality. At last, in addition to the inventiveness and unique way the first Freudian model of trauma connects its elements, a horizon of persistence to that approach is still affirmed in the sphere of the theory of generalized seduction.

Keywords: Trauma, theory of seduction, drive, infantile sexuality, theory of generalized seduction. 


\section{INTRODUÇÃO}

A reflexão sobre o trauma é um dos mais importantes eixos do movimento de ideias da teoria psicanalítica freudiana, estabelecendo com os conceitos de inconsciente, sexualidade e pulsão uma intensa dialética. Há disso vários exemplos. Freud supera Charcot no entendimento da histeria por enxergar uma inovadora lógica do trauma na etiologia da neurose. Em 1896, sua abordagem do trauma se tornaria ainda mais percuciente, configurando a chamada teoria da sedução, cuja organicidade requintada de elementos e dinâmica singular produziriam o primeiro modelo (na acepção plenamente epistemológica dessa palavra) do trauma. Mais adiante, no caso do Homem dos Lobos, publicado em 1918, Freud recorreria novamente ao modelo do trauma de 1896. Já em 1920, os sonhos traumáticos seriam focalizados pelo viés da compulsão à repetição, índice da pulsão de morte. Por fim, em 1926, a tentativa de síntese metapsicológica que Freud empreende em "Inibições, sintomas e angústia” traria à luz sua derradeira elaboração da questão do trauma. A palavra "trauma” é de origem grega e reporta-se à ferida que provém de uma penetração. Assim, o traumatizante seria sempre associado ao rompimento de uma estrutura de defesa. O caráter súbito, inesperado e ameaçador de acontecimentos extraordinários, a variedade desconcertante das formas de sua assimilação psíquica, a discrepância entre a recorrência duradoura do ataque interno pulsional e a finitude do evento externo, a desestabilização e a regressão psíquica que incidem sobre o sujeito e a peculiar dinâmica temporal e mnemônica da irrupção traumática apresentar-se-iam como os múltiplos e embaraçados fios do que poderíamos chamar de trama do trauma. O curso histórico do pensamento freudiano registraria essas várias faces do trauma, oscilando, porém, quanto ao peso epistemológico concedido a cada uma dessas dimensões aludidas.

\section{RUMO AO PRIMEIRO MODELO DO TRAUMA:} A CONSTITUIÇÃO DA TEORIA DA SEDUÇÃO

Se retrocedermos nossa atenção ao mistério oitocentista da histeria — objeto de grande esforço de elucidação por parte da medicina nas décadas finais daquela época - constatamos que a neurose maior (como o mal histérico era chamado na França) já era abordada por meio da noção de trauma. Essa conexão seria inicialmente sustentada por Charcot (1825-1893), com quem Freud estagiaria por cinco meses, a partir de outubro de 1885, no Hospital de Salpêtrière. Com o objetivo de livrar os quadros histéricos das habituais acusações de simulação, Charcot utilizava bastante a hipnose, em prestigiadas demonstrações, nas quais sintomas eram fabricados e apagados experimentalmente. Embora a índole neurótica da histeria fosse atribuída em última instância à hereditariedade, Charcot identificava a atuação de agentes provocadores, dentre os quais se destacava o trauma. 
Esse era o estado de coisas dominante, frente ao qual Freud, em suas primeiras publicações, ousará introduzir um ponto de vista alternativo. Ele reservará ao trauma uma participação diversa e mais importante no deslinde da questão. No texto "Sobre o mecanismo psíquico dos fenômenos histéricos: uma conferência” (1893), destacará a relevância do papel do trauma na histeria, recorrendo a uma hipotética suspensão da hereditariedade, a fundamental razão patogênica classicamente sustentada por Charcot:

"Consideremos o caso de uma pessoa sujeita a um trauma, sem antes ter estado doente, e talvez, mesmo sem ter qualquer predisposição hereditária. O trauma deve satisfazer a certas condições. Deve ser grave - isto é, ser de uma espécie que envolva a ideia de perigo mortal, de uma ameaça à vida. Mas não deve ser grave no sentido de pôr termo à atividade psíquica. De outra forma, não produziria o resultado que esperamos dele.” (FREUD, 1893/1994, p.37)

Podemos perceber que a atividade psíquica decorrente do trauma físico se insinua como tão importante como o aludido predicado de gravidade do fato. O raciocínio adotado é o de que o evento externo não produz por si mesmo o trauma, mas na verdade dispara uma atividade psíquica — esta sim, patogênica. Freud enfatizará esse posicionamento dizendo que “o que produz o resultado não é o fator mecânico, mas o afeto de terror, o trauma psíquico.” (1893/1994, p.40). Portanto, toda histeria pode ser compreendida como uma histeria traumática, pois responde sintomaticamente a uma atividade psíquica. Freud então afirmará que a dinâmica neurótica consiste na formação de uma dupla consciência, por meio de uma cisão entre afeto e representação. De um lado, há o afeto suscitado pelo evento, na forma de um quantum de excitação correspondente, que permanecerá retido em parte da psique pela inexistência ou incompletude de um movimento psíquico (de uma ab-reação) que deveria ter descarregado aquele excesso de estímulo produzido. De outro, em face dessa ausência ou insuficiência evacuatória, instalar-se-á, de modo correlato e representativo daquele afeto patologicamente preservado, o sintoma neurótico. Podemos notar que o mesmo configura uma conexão equivocada, por assim dizer (uma falsa ligação) entre o quantum de afeto e uma área corporal convertida (histericizada) ou uma representação deslocada (investida de forma obsessivo-compulsiva). Caberá à terapêutica religar o núcleo enquistado de afeto à representação original, via rememoração da cena traumática, de modo a drená-lo e, assim, estancar a produção de sintomas. Em suma, o que se propugnava naquele instante era refazer a sequência traumática, no âmbito clínico, proporcionando substitutivamente o necessário arremate catártico que outrora restara inacabado pela atividade psíquica regular do sujeito. 
Se até aqui Freud estabelecera a ligação entre a sintomatologia da histeria e um trauma psíquico, que se define pelo desencadeamento de uma atividade mental inconclusa e dissociativa, em "A hereditariedade e a etiologia das neuroses" (1896), dará mais um passo adiante, e apresentará finalmente a tese da natureza sexual do trauma. De forma solene e como resultado de ampla pesquisa, reivindicase agora à experiência sexual precoce o estatuto de fator fundamental na causa das psiconeuroses de defesa, em assumido contraste e confronto com a tradicional tese da hereditariedade nervosa, outrora firmada por Charcot. Esse novo entendimento resulta, de acordo com Freud, da aplicação de um novo recurso - a psicanálise - método peculiar que é atribuído a Breuer. O texto "A hereditariedade e a etiologia das neuroses" (1896) abriga o primeiro registro publicado da palavra “psicanálise”. Trata-se, segundo Freud, de um procedimento exploratório "um pouco intrincado, mas insubstituível, tal a fertilidade que tem demonstrado para lançar luz sobre os obscuros caminhos da ideação inconsciente" (FREUD, 1896a/1994, p.150). Ele ressalta a eficácia da psicanálise em determinar a origem dos sintomas, afirmando que a investigação acurada e retrospectiva da vida do paciente, pela qual se vai tecendo a complexa articulação de suas representações psíquicas, permite-nos verificar que, em todos os casos, um determinado agente esteve especificamente presente na eclosão da histeria.

“Esse agente é, de fato, uma lembrança relacionada à vida sexual, mas que apresenta duas características da máxima importância. O evento do qual o sujeito reteve uma lembrança inconsciente é uma experiência precoce de relações sexuais com excitação real dos órgãos genitais, resultante do abuso sexual cometido por outra pessoa; e o período da vida em que ocorre esse evento fatal é a infância — até a idade de 8 ou 10 anos, antes que a criança tenha atingido a maturidade sexual. Uma experiência sexual passiva antes da puberdade: eis portanto a etiologia específica da histeria.” (FREUD, 1896a/1994, p.151)

Estamos, pois, diante do que se chamou teoria da sedução. O infante, numa condição de passividade, sofreria a ação sexual de um adulto ou de outra criança, originando o implante de um potencial traumático que permanecerá adormecido, num primeiro momento - até que uma lembrança inconsciente, a ocorrer no futuro, produza a ressignificação do evento como experiência sexual, por parte da vítima, fazendo com que o sintoma neurótico então se manifeste.

\section{DISCUSSÃO DOS COMPONENTES E MECANISMOS DO MODELO ETIOLÓGICO DE 1896}

A teoria da sedução articulará neurose e trauma, pela mediação de um aspecto fático (o atentado sexual) e um psíquico (a memória ressignificante). Relevante observar que em “A etiologia da histeria” (1896), Freud reafirmará categorica- 
mente a experiência sexual passiva infantil em seu valor heurístico e empírico de novo e seguro ponto de abordagem da neurose, ao assinalar o seguinte: "qualquer que seja o caso e qualquer que seja o sintoma que tomemos como ponto de partida, no fim chegamos infalivelmente ao campo da experiência sexual." (FREUD, 1896b/1994, p.196). Podemos constatar que a experiência do atentado sexual aparece na forma de uma predisposição, o que nos indica que, na verdade, a etiologia neurótica preconizada pelo autor não opera de forma mecânica, mas é, na verdade, decorrente de um processo complexo, composto por momentos conjugados, já que o fator predisponente sempre exigirá interligação com um cofator para a instauração do trauma.

"Sustentamos, portanto, que as experiências sexuais infantis constituem a precondição fundamental da histeria, que são, por assim, dizer, a predisposição para esta, e que são elas que criam os sintomas histéricos - mas não o fazem de imediato, permanecendo inicialmente sem efeito e só exercendo uma ação patogênica depois, ao serem despertadas, após a puberdade, sob a forma de lembranças inconscientes." (FREUD, 1896b/1994, p.207)

E ainda: "nas pessoas histéricas, quando há uma causa precipitante atual, entram em ação as antigas experiências sob a forma de lembranças inconscientes." (idem, p.213). Mas, afinal, em que momento o trauma se instala? No texto "Observações adicionais sobre as neuropsicoses de defesa” (1896c), Freud utiliza várias vezes as expressões trauma infantil e traumas infantis, o que aparentemente nos conduziria a situar o traumático no âmbito do atentado sexual. No entanto, já advertira que "não são as experiências em si que agem de modo traumático, mas antes sua revivescência como lembrança depois que o sujeito ingressa na maturidade sexual.” (FREUD, 1896a/1994, p.165). Portanto, vê-se que sua opção é por localizar o pathos traumatizante no momento do efeito singular da lembrança, a saber: naquela revivescência mnemônica da experiência arcaica por sua ressignificação em termos sexuais. Mas a expressão trauma infantil, fartamente utilizada por Freud, pode ser referida, em nosso entendimento, ao resultado da implantação de uma potência que agirá no futuro, já que o atentado sexual representou uma invasão, por ora inativa, mas cujos efeitos aparecerão a posteriori. Nesse âmbito, nos remeteríamos ao trauma em sua acepção de efração, ou seja, de ruptura penetrante. Mas se quisermos nos referir ao momento propriamente inaugural da desorganização psíquica, teremos de privilegiar o instante da ação patogênica — aquele da significação sexual a posteriori do atentado sedutor, deflagrado pela lembrança. É visível o quanto a primeira teoria do trauma fundamenta-se num modelo da psique como um aparelho de memória das experiências intersubjetivas, que se transforma dialeticamente em sistema de conflito inconsciente-consciente, em face da 
atribuição de significado sexual — a posteriori — a um evento de abuso infantil. Recapitulando os momentos já descritos, teríamos: 1) a inscrição psíquica de um traço de memória (a experiência do abuso, por assim dizer, "depositada” no sujeito); 2) a ativação desse traço de memória (a experiência infantil ressignificada); 3) O recalcamento dessa representação inadmissível ("o abuso era sexual”) com a cisão representação/excitação afetiva; 4) o retorno do recalcado nos sintomas neuróticos: conflito psíquico. Nesse contexto, é imprescindível o registro de que a teoria do trauma em dois tempos traz consigo a primeira elaboração psicanalítica a respeito do recalcamento, que se articula à sexualidade e ao conflito psíquico. Segundo Freud,

“a eclosão da histeria pode ser quase que invariavelmente atribuída a um conflito psíquico que emerge quando uma representação incompatível detona uma defesa por parte do ego e solicita um recalcamento. (...) A defesa cumpre seu propósito de arremessar a representação incompatível para fora da consciência quando há cenas sexuais infantis presentes no sujeito (até então normal) sob a forma de lembranças inconscientes (...)." (FREUD,1896b/1994, p.206)

Cumpre-nos o alerta de que esta teoria do trauma calcada na sedução sexual tem seu registro temporal a partir de dois marcos bem específicos: $1^{\circ}$ ) um acontecimento de abuso infantil e $2^{\circ}$ ) uma lembrança ativadora daquele depósito traumático até então inócuo. Trata-se de uma “operação póstuma de um trauma sexual na infância” (FREUD, 1896c/1994, p.167). Tal “operação”, no entanto, se dá pelo poder patogênico ressignificante da lembrança. Portanto, o segundo evento - o propiciador da lembrança — é desprezado axiologicamente por Freud.

A rigor, o segundo evento apenas acende a luz da lembrança, mas não dispara o gatilho do trauma, ou seja, não integra a cadeia traumatizante ativando a experiência infantil. Fenomenologicamente, os acontecimentos posteriores suscitarão a lembrança inconsciente patogênica por meio de associações. Mas em termos de lógica do trauma, o que vale é apenas a relação entre dois termos: uma dialética entre um primitivo acontecimento abusivo ainda não significado e sua lembrança ressignificante, entre os quais se insere sua inocuidade temporária posteriormente transformada, em reativação traumática, a partir de um conhecimento adquirido pela vítima sobre a sexualidade ao longo de seu amadurecimento.

Questão instigante diz respeito ao grau de consciência do sujeito, no momento da ressignificação sexual de sua experiência infantil. Haveria algum flash de consciência do cunho sexual da experiência vivida - imediatamente recalcado? Ou a lembrança, isto é, a ligação representativa entre o evento primitivo e sua natureza sexual processa-se no plano inconsciente, formando daí a expressão, algo paradoxal: "lembrança inconsciente”? Freud não esclarece esse ponto. 
Mas entendemos que o imprescindível é observar que a teoria do trauma articulada à sedução infantil coloca o momento tradutivo, a saber, o momento da significação sexual da experiência subjetiva como a verdadeira efetividade detonadora do trauma. Devemos ter em mente que a transição freudiana do trauma psíquico para o trauma sexual como fator etiológico das neuroses decorreu justamente da dificuldade que Freud sentia em acatar sem maiores questionamentos a hipótese de que qualquer acontecimento poderia ser assimilado pelo sujeito na qualidade de psiquicamente traumatizante.

Esse ponto de vista até então dominante — que passa a ser questionado sistematicamente por Freud - parecia encontrar amparo em experiências com a hipnose, através das quais determinações triviais eram então elevadas a um estatuto traumático para o indivíduo hipnotizado. Tal fato se correlacionava de maneira intensa com certas associações levadas a efeito por pacientes, quando seus estados patológicos eram vinculados mnemonicamente a eventos banais. Ao lado disso, ia ao encontro da tese de Breuer, segundo a qual supostas ocorrências extraclínicas de um estado hipnoide no sujeito possibilitariam psiquicamente uma marcação traumática naquele, a despeito da insignificância objetiva do fato.

Mas se Freud sabe, por um lado, que o traumático se inscreve por meio de uma atividade mental (a tese do trauma psíquico), por outro, ele de fato não se sente à vontade para dispensar uma relação de adequação entre o movimento interno da psique, responsável pela irrupção sintomática, e a qualidade do evento externo. Assim, permanecia a incômoda indagação sobre se a teoria do trauma poderia apoiar-se num evento exterior de escassa significação — ou seja, se seria viável, para o entendimento que se construía, alicerçar-se parcialmente num fato desprovido de gravidade. Uma saída cogitada para esse impasse seria o aprofundamento radical da pesquisa sobre a etiologia do sintoma, de modo a se adotar uma política metodológica de sempre ultrapassar as associações ligadas a eventos de vetor atacante questionável, rumo a uma ideal rememoração de um acontecimento indiscutivelmente adequado à eclosão psíquica do trauma.

Mas Freud ressalta que essa via vai-se revelando, na experiência clínica, uma missão impossível: uma trajetória labiríntica e infinita. Mesmo quando o paciente, por fim, supostamente conseguia localizar um ponto de origem de seus sintomas - de apropriado valor patogênico aos olhos do analista - a posteridade do tratamento não tardava a revelar o aparecimento de novas cenas, até então desconhecidas e insuspeitas.

Podemos então notar que a preconização da etiologia sexual da neurose teria o condão de determinar um deslinde epistemologicamente eficiente para aquele interminável novelo de interconexões associativas com que a clínica se defrontava. E essa virtude ocorre na medida em que não funda o seu poder explicativo apenas na economia e na dinâmica de uma suposta cena originária (carecedora de 
ab-reação e, daí, clivante e patogênica), mas no significado de uma experiência infantil inconscientemente evocada.

O traço mnemônico que aciona a experiência infantil do atentado sexual será o fator que preservará tanto a tese da natureza psíquica do trauma quanto a adequação deste a um fato que não pode ser qualquer um, mas, sim, certo acontecimento qualificado axiologicamente pelo psiquismo humano - um evento, pois, sexual. O sexual surgia na teoria da sedução como uma experiência apassivante geradora de uma representação inconciliável, cuja inadmissibilidade frente ao eu se definia por sua censurabilidade moral. Segundo Freud, "os esforços defensivos do ego dependem do desenvolvimento moral e intelectual completo do sujeito" (1896b/1994, p.207). Introduzia-se, assim, o quesito da maturidade orgânicointelectiva da vítima, a fim de que a fugaz (pois recalcada) ressignificação da experiência infantil vivida (por meio da eclosão de sentimentos de asco, repúdio, vergonha, culpa, etc.) se fizesse justamente pelo índice de sexualidade condenável então identificado.

Destaquemos que essa aludida dependência da maturação dos órgãos sexuais na puberdade, bem como o correlativo conhecimento a respeito do normativo e do transgressivo, são itens que contrastarão com a futura ideia de sexualidade infantil, a ser desenvolvida em "Três ensaios sobre a teoria da sexualidade" (1905). De qualquer modo, tornando-se a eclosão do trauma vinculada a um aspecto específico de um movimento de ressignificação de evento pretérito, de ordem sexual, poder-se-ia agora responder por que, por exemplo, tanto a prosaica visão de uma borboleta como um grave acidente ferroviário poderiam ser relatados por pacientes como os momentos a partir dos quais surgiram seus sintomas.

A solução consistente que se apresenta é a seguinte: tanto o exemplo de evento ameaçador de fato quanto o outro, francamente débil quanto ao poder de produzir um efeito traumático, não fazem parte da lógica patogênica do trauma. Não é, pois, o segundo acontecimento ou um rol secundário de acontecimentos que exatamente desencadeiam o trauma. Eles desencadeiam, na verdade, o traço de memória traumatizante. Eles são, seja qual for sua natureza, agentes provocadores contingenciais da lembrança inconsciente - esta sim, a real ativadora do evento infantil, em termos patogênicos. Por serem evocados mais facilmente pela memória, os acontecimentos integrantes de um quadro de eventos secundários ao abuso infantil foram sempre associados com maior espontaneidade ao trauma pelos pacientes. Porém, ao entendê-los corretamente, como meros gatilhos mnemônicos, tanto faz se tais eventos posteriores ao atentado forem triviais ou terríveis e ameaçadores de fato.

Por isso, a opção freudiana pelo restrito entendimento do trauma através da primazia de um determinado evento infantil (qualificado como sexual) e de sua ativação posterior, excluindo-se o possível poder patogênico de uma segunda 
cena ou de cenas posteriores, terá a virtude de resolver o enigma da banalidade e da falta de adequação ao quadro traumático de uma plêiade de experiências trazidas à luz pelos pacientes, ingenuamente valorizadas por eles, mas, em realidade, imprestáveis para a específica composição da lógica traumática.

Observemos então que o sexual, na forma de uma experiência infantil, é o elemento que, no âmbito desta primeira teoria do trauma, retira o foco da particularidade do modo de assimilação psíquica (ab-reativo ou não) das experiências e o redireciona para o significado de uma determinada cena (seu sentido inaceitável à consciência), que é seu caráter efetivamente traumático. Com isso, a descoberta de que o trauma é sexual liberta a teoria e a clínica do puro empirismo psicologista das experiências não ab-reagidas e neurotizantes e coloca a reflexão e a prática defronte a um significado específico e exclusivo que se revelará o fundamento da neurose: a experiência apassivante da sexualidade por via do atentado sexual.

Desse modo, a primeira teoria do trauma de Freud não é biologista, pois não sustenta qualquer aposta etiológica fundamental na hereditariedade; não é mecanicista, pois não admite que o evento externo por si mesmo provoque diretamente o trauma; mas também não é psicologista, porque não reduz o traumático à contingência de uma forma de assimilação psíquica de eventos, quaisquer que sejam. Era, assim, notável a evolução pela qual havia passado o pensamento de Freud e sua complexa originalidade atingida nos anos 1895/1896, quando preconiza definitivamente a etiologia sexual da neurose, formulando uma teoria da sedução como teoria do trauma em dois tempos.

\section{O REFLUXO DA TEORIA DA SEDUÇÃO}

A autocrítica levada a cabo por Freud, no início do outono de 1897, a respeito de sua proposta de uma etiologia traumática da neurose, aparece em geral na historiografia psicanalítica como um revolucionário ponto de inflexão a partir do qual ocorreria o efetivo surgimento da psicanálise — tal como prevaleceria e se tornaria conhecida na posteridade. Partindo da então preconizada realidade factual da sedução infantil, o pensamento freudiano teria avançado para fundamentar-se na fantasia de sedução — o que representaria um inquestionável aperfeiçoamento de suas bases e de seu foco.

As dúvidas freudianas conducentes à transformação de seu ponto de vista aparecem na carta 69 a Fliess, de 21 de setembro de 1897.

"Querido Wilhelm, (...)

E agora quero confiar-lhe, de imediato, o grande segredo que foi despontando lentamente em mim nestes últimos meses. Não acredito mais em minha neurótica |teoria das neuroses|. (...) A |incidência| da perversão teria que ser incomensura- 
velmente mais frequente do que a histeria |dela resultante|, porque afinal, a doença só ocorre quando há um acúmulo de acontecimentos e um fator contributivo que enfraqueça a defesa. (...)

Agora, não tenho a menor ideia de onde me situo, pois não tive êxito em alcançar uma compreensão teórica do recalcamento e de sua inter-relação de forças. Mais uma vez, parece discutível que somente as experiências posteriores deem ímpeto às fantasias, que, |então| remontariam à infância, e, com isso, o fator da predisposição hereditária recupera uma esfera de influência da qual eu me incumbira de desalojálo - em prol do esclarecimento da neurose." (MASSON, 1985, p.265-266)

Embora a sinalização de um retorno à hereditariedade charcotiana jamais se tenha consumado, Freud notava com gravidade e pesar que sua teoria da sedução fundava-se numa improbabilidade estatística, já que a quantidade de pacientes histéricos com reminiscências a respeito de atentados de sedução ultrapassava amplamente o número de pacientes com sintomatologia neurótica. O corolário disso seria a existência de um quantitativo de perversos — nos próprios meios familiares - muitíssimo superior ao que seria razoável supor, para que se tornasse possível sustentar aquela ampla gama de lembranças quanto a abusos e atos de sedução infantil.

É a essa situação implausível que Freud parece se referir em certo momento da mesma carta 69, quando revela a "percepção da inesperada frequência da histeria, com predomínio precisamente das mesmas condições em cada caso, muito embora, certamente, essas perversões tão generalizadas contra as crianças não sejam muito prováveis” (MASSON, 1985, p.265).

Com efeito, a constatação clínica de um instigante padrão e de uma inusitada regularidade nas falas de pacientes histéricos, fatos aludidos por Freud como francamente inesperados, resultará na ruína da tese da permanente empiricidade do atentado sexual como causador da neurose e pavimentará a introdução da suspeita de contaminação dos relatos por parte de puros movimentos de fantasia histérica (desprovidos, pois, de lastro no abuso infantil). A vantagem da hipótese da hegemonia da fantasia é que essa se apresenta aos olhos de Freud como fator dotado de plena aptidão para sustentar a surpreendente e extensa similaridade entre os relatos clínicos. Embora parte dos psicanalistas antagonize a teoria da sedução com a inflexão crítica de 1897, apontando essa última como introdutora de uma radical inovação doutrinária - a refletir o amadurecimento do pensamento freudiano - é bom que se diga que a questão da fantasia jamais restara inexistente na etiologia traumático-sexual da neurose presente na teoria da sedução.

Freud salienta, na dita carta 69, que lhe parece "discutível que somente experiências posteriores deem ímpeto às fantasias que então remontariam à infância” (idem, p.266). Ora, contrariando a historiografia simplificadora da 
psicanálise, tal passagem supracitada nos mostra inequivocamente a ausência de um antagonismo dicotômico entre trauma e fantasia no âmbito da teoria da sedução. Podemos verificar no texto em foco que as experiências posteriores configuradoras do segundo rol de eventos na fenomenologia do trauma constituem o momento de incitação e de irrupção de lembranças cujo poder patologizante (pois ressignificador) do evento abusivo infantil operará justamente através da deflagração de fantasias.

Portanto, o processo de eclosão neurótica, como aparece na teoria da sedução, iniciou-se precisamente no aludido "ímpeto às fantasias", ou seja, na inevitável instigação fantasmática e em seu efeito atacante que são indiscerníveis da reminiscência. A lembrança traumatizante opera carregando-se de uma face gozosa - a fantasia - que, por sua vez, só pode ser suscitada e tecida a partir de uma dimensão mnemônica, ínsita à reminiscência.

Nossa conclusão é a de que nesse trecho da carta do equinócio de 1897 explicita-se o que restava implícito, mas em pleno vigor, na teoria da sedução: lembrança e fantasia são correlativas e contrafaciais na irrupção traumática, por via da ressignificação do evento passado infantil. Na esteira disso, diríamos que o mérito da teoria do trauma em dois tempos consistiria, entre outras coisas, em demonstrar a íntima articulação entre memória, gozo, ataque fantasmático, defesa, recalque e retorno do recalcado.

Se o ser humano fantasia, ele só o pode fazer pela operação da lembrança traumática; ainda, lembrar é inevitavelmente gozar de uma fantasia atacante imediatamente formada no próprio momento e seio do que é lembrado. Enfim, contrariamente aos comentadores que de modo apressado elegem a suposta introdução da fantasia na cena teórica psicanalítica como o elemento de diferenciação entre o pensamento freudiano pré e pós-equinócio de 1897, o mais correto é sustentar que o que separou um momento do outro jamais foi a presença ou a ausência da noção de fantasia, mas sim a especificação da origem da fantasia que cada um deles registrou explícita ou implicitamente.

\section{UM NOVO PARADIGMA: A SEXUALIDADE INFANTIL E PULSIONAL}

Após 1897, a origem e fundamento da fantasia não mais será a vivência apassivadora infantil, por assim dizer revisada mnemonicamente como sexual, mas a própria sexualidade infantil, como evento universal e biológico produzido por um fator a que Freud daria o nome de Triebe (impulso, pulsão) - introduzido em 1905, no texto "Três ensaios sobre a teoria da sexualidade”. A revolucionária ampliação efetuada nessa obra quanto à determinação do início e das fronteiras da sexualidade - que passa de fenômeno genital tutelado pela puberdade para um fenômeno autoerótico já em plena positividade e vigên- 
cia na aurora da vida infantil — só se torna possível através da mencionada introdução do conceito de pulsão, que funcionará como a força de pressão subjacente àquela fenomenologia sexual arcaica, que então poderá ser entendida como biológica e infantil, e, daí, universal e não traumática. Por isso, logo nas primeiras linhas de "Três ensaios sobre a teoria da sexualidade", Freud entrelaçará sexualidade, fundamento biológico e postulado pulsional, ao escrever que "o fato da existência de necessidades sexuais no homem e no animal expressa-se na biologia pelo pressuposto de uma 'pulsão sexual'," (FREUD, 1905/1994, p.127). Isso quer dizer que a sexualidade só pode ser cientificamente compreendida postulando-se a presença de um estímulo específico — de fonte somática — que precede e rege aquele conjunto singular de manifestações, efeitos e vicissitudes nos seres vivos. Nessa mesmíssima linha, uma passagem de "Pulsões e destinos da pulsão":

\begin{abstract}
“Se abordarmos agora a vida psíquica do ponto de vista biológico, a "pulsão" nos aparecerá como um conceito limite entre o psíquico e o somático, como o representante psíquico dos estímulos que provêm do interior do corpo e alcançam a psique, como uma medida de trabalho imposta ao psíquico em consequência de sua relação com o corpo.” (FREUD, 1915/2004, p.148)
\end{abstract}

Atenção para as expressões: vida psíquica do ponto de vista biológico; estímulos que provêm do interior do corpo; medida de trabalho imposta ao psíquico em consequência de sua relação com o corpo. Todas elas nos mostram que no freudismo pós-teoria da sedução, a sexualidade tornara-se um epifenômeno desse postulado biológico denominado Triebe (pulsão), que Freud compreendia, por um lado, como singularidade interna ao sujeito, e, por outro, como estimulação análoga àquela produzida pela realidade em nossos sentidos. Assim, tanto o corpo quanto o mundo exterior têm como predicado essencial e comum o fato de ambos serem fontes de estímulos que provocarão a necessidade de um processamento evacuatório por parte do aparelho psíquico, cuja função de redutor daquelas sensações e tensões recebidas e acumuladas é sua própria razão de ser.

Com efeito, procedeu-se no pensamento freudiano à substituição do sexual como instância traumática — em virtude do encontro a posteriori do sujeito, no curso de sua existência, com certa significação relativa a evento interpessoal de sua infância — pelo ponto de vista que apresenta a sexualidade como um campo das manifestações polimórficas, perversas e fantasísticas - oriundas do investimento de uma força pressionante de fundo somático e de operacionalidade representativa na psique, a que se deu o nome de pulsão.

Assim, o conflito psíquico fundado na sedução infantil, em face de reminiscências/fantasias traumáticas, pois inaceitáveis — deflagradoras de uma defesa - a partir 
de agora será substituído por um modelo em que um determinado fenômeno biológico e universal, intitulado sexualidade infantil, propiciado por fontes orgânicas de estimulação pulsional, percorrerá um desenvolvimento por etapas, através de fases de investimento e de organização libidinal (oral, anal, fálica) em direção a certa síntese derradeira, sob a hegemonia da genitalidade.

Cabe-nos lembrar que esse processo sequencial desenrola-se de modo multifacetado e por vezes acidentado: apresenta-se sujeito a vicissitudes, tais como inibições, fixações e regressões, contrai-se numa fase de latência, atinge seu coroamento na genitalidade-reprodutiva, bem como exibe um variado leque de destinação pulsional, nas vias do recalque, da sublimação, etc. Freud registraria, enfim, a mudança de enfoque e da correção de curso ocorrida em seu pensamento, que teria efetuado a substituição dos traumas sexuais infantis pela descoberta do infantilismo da sexualidade. (FREUD,1906/1994, p.258)

\section{CONCLUSÃO: UM MODELO DO TRAUMA DOTADO DE VIÉS ANTROPOLÓGICO}

O "calcanhar de Aquiles" da teoria da sedução — a postulação da universalidade do atentado perverso sobre a criança — tornou-se tema de domínio público, explorado ad nauseam no campo doutrinário da psicanálise, recalcando as virtudes subsistentes da sofisticada articulação lógica e fenomenológica contida em seu modelo de entendimento do trauma. Consideramos o primeiro modelo do trauma — presente na teoria da sedução de 1896 — um impressionante tour de force. Ele é revelador da magnitude do gênio de Freud, pela capacidade que possui de articular dialeticamente uma série de elementos — de forma bastante engenhosa. Simultaneamente, o que exsurge como grandioso nas bases daquela teorização é a dimensão antropológica que se insinua. Subjacente ao esquema de causação traumática da neurose, vislumbra-se uma visão de homem profunda, complexa, multifacetada:

a) A subjetividade humana é indiscernível da categoria de intersubjetividade - o trauma só pode ser pensado a partir do encontro do sujeito com a alteridade: um encontro marcante com o outro, marcado pelo outro;

b) No humano, ser e temporalidade se conjugam - a inscrição dos eventos no psiquismo não é feita de forma imediata, direta, mecânica, mas requer um duplo tempo para a irrupção de seus efeitos;

c) No humano, o tempo só é tornado ser pela mediação de um significado (que então configura o segundo tempo do trauma) e esse significado é referente ao campo sexual como dimensão intolerável e atacante ao eu, e daí destinada ao recalcamento; 
d) No humano, a significação encontra-se mnemonicamente magnetizada pelo inconsciente. Significar é sempre recordar sem perceber (e sem poder perceber) que se recorda: é associar, num átimo, consciente e inconsciente. Daí a expressão freudiana ambígua, fluida, misteriosa, mas reveladora: lembrança inconsciente - indicando-nos que a conexão mnemônica entre tempos e eventos, por um significado, pode ser recalcada de imediato e produzir efeitos psíquicos sem que o sujeito tenha racionalmente atinado com esse processo de si sobre si mesmo;

e) O ser humano traumatiza-se porque nele acontece o inusitado: o traço de memória então ressignificado como inconciliável torna-se, a despeito disso, fantasia de desejo e ataque pulsional. A passividade é um gozo paradoxal: é desejo (inconsciente) e angústia (consciente).

Eis o retrato panorâmico, percuciente, operacional e absolutamente vertiginoso em seu paradoxo que Sigmund Freud, em 1896, logrou revelar a respeito da psique humana, de maneira audaciosa e revolucionária. A primeira teoria do trauma é, portanto, uma complexa articulação entre várias dimensões metapsicológicas e antropológicas: a fática (intersubjetiva), a significacional (sexual), a temporal (mnemônica), a inconsciente (a recalcada ressignificação do evento), a etiológico-pulsional (o retorno do recalcado pelos sintomas neuróticos) e a conflitualintersistêmica (o que é prazer para o inconsciente é desprazer para o consciente). Na teoria da sedução, o trauma é sexual. Essa palavra — sexual — adquire aqui o estatuto de uma experiência tão marcante, tão singular para o ser humano que ganha a dimensão de parâmetro de memória e critério de recepção face às vicissitudes que acometerão o sujeito em sua existência futura. A sexualidade é, antes e acima de tudo, um tempo ao qual o homem remeter-se-á mnemonicamente vida afora, e que ressurgirá por via de um efeito neurótico, que é, afinal, efeito pulsional. Daí o diálogo que a teoria da sedução pode estabelecer com uma magistral passagem de Walter Benjamin: "Pois um acontecimento vivido é finito, ou pelo menos encerrado na esfera do vivido, ao passo que o acontecimento lembrado é sem limites, porque é apenas uma chave para tudo o que veio antes e depois." (BENJAMIN, 1985, p.37)

Nesse trecho, Benjamin mostra-nos que o vivido não passa de um depósito, um traço, uma inscrição — que nesse nível se encerra, mas que será inevitavelmente ativado (ressignificado) pela lembrança (segundo tempo do trauma), tornando-se “sem limites”, ou seja, produzindo (em tradução psicanalítica) efeito pulsional - e nesse instante transformando-se em "chave" para o que veio antes (a sedução) e para o que veio depois (os ataques de fantasias, os sonhos, a neurose, a compulsão repetitiva etc.).

Eis uma dialética da memória, que é a dialética da existência humana sexualizada intersubjetivamente em seu próprio originário, superando o paradoxo do atentado, através 
de uma sedução não contingente, mas generalizada e universal (LAPLANCHE, 1988, p.108-125), visto que transformadora do finito (o vivido) em infinito: objetofonte de pulsão — para sempre causa de desejo.

Recebido em 15/4/2011. Aprovado em 11/6/2011.

\section{REFERÊNCIASS}

ANDERSON, O. (2000) Freud precursor de Freud. São Paulo: Casa do Psicólogo.

BENJAMIN, W. (1985) Magia e técnica, arte e política. São Paulo: Brasiliense.

FREUD, S. (1994) Edição standard brasileira das obras completas de Sigmund Freud.

Rio de Janeiro: Imago.

(1893) "Sobre o mecanismo psíquico dos fenômenos histéricos: uma conferência, v.III, p.37-47.

(1896a) “A hereditariedade e a etiologia das neuroses", v.III, p.143155.

(1896b) “A etiologia da histeria”, v.III, p.189-215.

(1896c) "Observações adcionais sobre as neuropsicoses de defesa", v.III, p.163-183.

(1905) “Três ensaios sobre a teoria da sexualidade”, v.VII, p.118230.

(1906) "Minhas teses sobre o papel da sexualidade na etiologia das neurose”, v.VII, p.253-263.

(2004) Obras psicológicas de Sigmund Freud: escritos sobre a psicologia do inconsciente. Rio de Janeiro: Imago.

(1915) “Pulsões e destinos da pulsão", v.1, p.133-173.

LACAN, J. (1964/1985) O Seminário livro 11, Os quatro conceitos fundamentais da psicanálise. Rio de Janeiro: Jorge Zahar Editor.

LAPLANCHE, J. (1988) Teoria da sedução generalizada e outros ensaios. Porto Alegre: Artes Médicas.

. (1992) Novos fundamentos para a psicanálise. São Paulo: Martins Fontes.

MASSON, J. (1986) A correspondência completa de Sigmund Freud para Wilhelm Fliess 1887-1904. Rio de Janeiro: Imago.

MEZAN, R. (1991) Freud: a trama dos conceitos. 3 ed. São Paulo: Perspectiva.

RAPAPORT, D. (1982) A estrutura da teoria psicanalítica. São Paulo: Perspectiva.

RIBEIRO, P. C. (1996) Sedução generalizada e primazia do sexual. Percurso: Revista de Psicanálise, ano VIII, n.16, São Paulo: Instituto Sedes Sapientiae, p.49-57. 
ROBERT, M. (1991) A revolução psicanalítica. São Paulo: Perspectiva. RUDGE, A. (2009) Trauma. Rio de Janeiro: Jorge Zahar Editor.

UCHITEL, M. (2001) Neurose traumática. São Paulo: Casa do Psicólogo.

Antônio Luiz Pereira de Castilho anluiz@yahoo.com 